\title{
Changes of Physiological Characteristic Indexes in the Aging Process of the Liquid Spawn of Auricularia auricula
}

Jong Chol ${ }^{1}$, Jin Myongl ${ }^{2}$, Choe Sunl ${ }^{2}$, Zhu HaiFeng ${ }^{3}$, Li DeTian ${ }^{3}$, Jo TaeYun ${ }^{1}$, Kim GyongChol ${ }^{1}$

${ }^{1}$ College of Agriculture, Haeju Kim JeWon University of Agriculture, Haeju 999093, Democratic People's

Republic of Korea

${ }^{2}$ Sariwon Kye UngSang University of Agriculture, Sariwon 950003, Democratic People's Republic of Korea

${ }^{3}$ College of Resources and Environment, Northeast Agricultural University, Harbin, China

\section{Article Info}

Volume 8 Issue 1

Page Number : 204-215

Publication Issue :

January-February-2021

\section{Article History}

Accepted : 01 Jan 2021

Published : 10 Jan 2021

\section{ABSTRACT}

In order to explore the change rule of physiological indexes during the aging process of the liquid spawn of Auricularia auricula, this test chooses three species of Auricularia auricula(Hei29, Heiweibanjin and Heiweidanpian), which treasured the activities of antioxidant enzymes, antioxidant substances, membrane peroxidation degree and reactive oxygen concentration during different mycelia age. The conclusion showed that: at the same mycelial age, the vitality of Heiweidanpian was the strongest, Hei29 followed, and Heiweibanjin was the weakest; with the increase of mycelia age, Catalase (CAT) activity, Ascorbic Acid(ASA) content, Malondialdehyde (MDA) content and $\mathrm{O}^{2-}$ production rate of the three kinds of Auricularia auricula increased continuously. Among them, ASA content, MDA content and $\mathrm{O}^{2-}$ production rate increased significantly, while Superoxide Dismutase (SOD) activity decreased significantly; although the Proline (Pro) content and electrical conductivity of the three kinds of Auricularia auricula showed different trends, which decreased significantly at 14 to $16 \mathrm{~d}$ and increased significantly at 8 to $10 \mathrm{~d}$, respectively, and $\mathrm{H}_{2} \mathrm{O}_{2}$ content increased significantly at 12 to $16 \mathrm{~d}$. It can be seen that SOD activity, CAT activity, ASA content, MDA content and $\mathrm{O}^{2-}$ production rate have significant regular changes during the aging process of the liquid spawn of Auricularia auricula.

The quantitative analysis found that when the MDA content is $1.42^{\sim} 1.72$ $\mu \mathrm{mol} \cdot \mathrm{g}^{-1}$, the $\mathrm{H}_{2} \mathrm{O}_{2}$ content is $3.4^{\sim} 4.3 \mu \mathrm{mol} \cdot \mathrm{g}^{-1}$ or the $\mathrm{O}^{2-}$ production rate is 9.5 $12.1 \mu \mathrm{mol} \cdot \mathrm{g}^{-1} \cdot \mathrm{min}^{-1}$, it can be considered Auricularia auricula just started to age or the aging degree is relatively low.

Keywords : Auricularia auricula, liquid spawn, aging, physiological index, edible fungus

Copyright : (C the author(s), publisher and licensee Technoscience Academy. This is an open-access article distributed under the terms of the Creative Commons Attribution Non-Commercial License, which permits unrestricted noncommercial use, distribution, and reproduction in any medium, provided the original work is properly cited 


\section{INTRODUCTION}

Auricularia auricula is a precious colloid fungus used for medicine and food, and its industry has developed rapidly [1]. However, the aging of the liquid spawn of Auricularia auricular has always been a prominent problem in the factory production process of Auricularia auricula, which will affect the yield and quality of Auricularia auricula and cause great economic loss to the producer.

In the liquid culture process of Auricularia auricula mycelia, with the increase of mycelia age and the consumption of nutrients, there will be the aging phenomenon.

The mycelia vitality of the aging strains decreased, the germination rate and growth rate decreased, the ability to resist bacteria was poor, the secretion of pigment increased, the number of hollow vacuoles increased, and even the rupture of cells and the lock like association decreased [2].

After the aging strains were inserted into the culture material, they showed slow growth of mycelia, weak resistance to bacteria, late ear emergence, increased contamination rate of bacterial inclusion, decreased yield and decreased quality of Auricularia auricula [3]. Studies have shown that excessive accumulation of reactive oxygen species (ROS) can damage organelles, lead to the deepening of membrane lipid peroxidation, and accelerate the aging process.

In response to the damage caused by reactive oxygen species, cells have evolved a complex enzymatic and non-enzymatic antioxidant system, which can help remove the ROS produced [4-5], Namal P, et al. found that the number of mitochondria, the content of malondialdehyde (MDA), and the activity of peroxidase are significantly correlated with aging [6]. Liu Zhanli, et al. found that the activity of acid phosphatase decreased with the increase of mycelia age [7].

In conclusion, the changes of related physiological indexes in the aging process of Auricularia auricula have a certain regularity, which can be used to qualitatively and quantitatively evaluate the aging process of Auricularia auricula. However, there is still a lack of systematic research on the changes of aging physiological indexes of agaric, which is not conducive to our in-depth understanding of the physiological mechanism of agaric aging.

In this paper, the change rules of related physiological indexes in the aging process of three kinds of Auricularia auricula were determined, to reveal the relationship between Auricularia auricula aging and the changes of various indexes, and provide a scientific basis for in-depth understanding and evaluation of the aging process of agaric.

\section{MATERIALS AND METHODS}

\subsection{Materials}

\section{(1) Test strains}

Hei29, Heiweibanjin and Heiweidanpian were purchased from the Heilongjiang Institute of Microbiology.

They were cultured in plate medium for $7 d$ for activation.

\section{(2) Test medium}

PDA medium: potato $200 \mathrm{~g}$, glucose $20 \mathrm{~g}$, agar $20 \mathrm{~g}$, distilled water $1000 \mathrm{~mL}$, natural $\mathrm{pH}$.

\subsection{Methods}

\section{(1) Determination of the aging time}

The solid strains were cultured in the petri dish, and after being grown, the mycelium blocks (with a diameter of $1 \mathrm{~cm}$ ) were cut with a perforator at the same radius from the inoculation and then inserted into the liquid medium. The mycelium pellets with a diameter of $1 \mathrm{~mm}$ were selected under sterile conditions and cultured in the PDA plate medium under the condition of $25^{\circ} \mathrm{C}$ and $160 \mathrm{r} \cdot \mathrm{min}^{-1}$ without light shock.

Every day, mycelium blocks of the same size were transferred to the center of the test solid plate medium with a puncher and cultured in a constant temperature incubator at $25^{\circ} \mathrm{C}$ in the dark. The germination was observed every day, and the 
mycelium diameter was measured from three directions of mycelium growth and the growth rate was calculated. After culture, mycelium was put into a centrifuge, centrifuged at $4000 \mathrm{rpm}$ for $10 \mathrm{~min}$, washed repeatedly with distilled water for 3times, then the supernatant was poured out, dried in an oven at $80^{\circ} \mathrm{C}$ to constant weight, and the dry weight of mycelium was weighed.

\section{(2) Sample preparation}

Samples were taken from the liquid medium for 5 times at an interval of $2 \mathrm{~d}$ on the 8th day, with an average period of $18 \mathrm{~d}$. After centrifugation, $2 \mathrm{~g}$ of mycelia were taken for subsequent experiments.

\section{(3) Physiological indexes in the aging process of three} kinds of test strains

\section{Antioxidant enzyme determination}

The homogenate was ground in the ice bath and centrifuged at $4^{\circ} \mathrm{C}, 8000 \mathrm{r} \cdot \mathrm{min}^{-1}$ for $10 \mathrm{~min} .4 .0 \mathrm{~mL}$ $0.05 \mathrm{~mol} \cdot \mathrm{L}^{-1} \mathrm{pH} 7.0$ of PBS, $0.3 \mathrm{~mL} 1.25 \mathrm{mmol} \cdot \mathrm{L}^{-1} \mathrm{NBT}$, $0.3 \mathrm{~mL} \quad 0.22 \mathrm{~mol} \cdot \mathrm{L}^{-1}$ methionine and $0.2 \mathrm{~mL}$ SOD enzyme solution were added into the test tube. After mixing, $0.3 \mathrm{~mL} 0.033 \mathrm{mmol} \cdot \mathrm{L}^{-1}$ methionine was added. The tubes were placed in an incubator under $4000 \mathrm{~lx}$ fluorescent lamp at $25^{\circ} \mathrm{C}$ and reacted for $15 \mathrm{~min}$. Four pairs of care were set, and SOD enzyme solution was replaced with PBS. One of them was placed in the dark for control. OD value was measured at $560 \mathrm{~nm}$ wavelength.

The extraction method of enzyme liquid for the determination of POD and CAT was the same as that for SOD. The method of $\mathrm{Xu}$ Jie, et al. was used for the determination of POD activity [8], and the method of CAT activity was determined according to Hamid et al. [9].

\section{$\sim$ Non-enzymatic antioxidant substances}

The ascorbic acid content was determined by referring to Tai et al. 's method, and a slight modification was made on this basis [10]: $0.5 \mathrm{~mL}$ of ASA extract was absorbed into the colorimetric tube, and $0.2 \mathrm{~mL}$ of $\mathrm{NaH}_{2} \mathrm{PO}_{4}\left(0.15 \mathrm{~mol} \cdot \mathrm{L}^{-1}\right.$, pH 7.4) solution and $0.2 \mathrm{~mL}$ of deionized water were added and mixed uniformly. After 30s, $0.4 \mathrm{~mL} 10 \%$ TCA solution, $0.4 \mathrm{~mL} 44 \% \mathrm{H}_{3} \mathrm{PO}_{4}, 0.4 \mathrm{~mL} 4 \%$ dipyridine (prepared with $70 \%$ ethanol) and $0.2 \mathrm{~mL} 3 \% \mathrm{FeCl}_{3}$ were added, mixed and sealed, and kept at $37^{\circ} \mathrm{C}$ water bath for $1 \mathrm{~h}$, then OD value at $525 \mathrm{~nm}$ was determined. The content of proline was determined according to the method of Madosa Emilian, et al. [11].

\section{Degree of membrane lipid peroxidation}

MDA content was determined by Thiobarbituric Acid (TBA) method.

Based on Mohammad Rezaee,et al. [12], the measurement of relative conductivity was slightly improved: $2 \mathrm{~g}$ of mycelia were taken with tweezers, washed with deionized water, placed in $60 \mathrm{~mL}$ of deionized water, soaked and shaken several times at room temperature, and the conductivity of mycelium leaching solution was measured with DDS-11A conductivity meter. After measuring, boil in boiling water and cool to room temperature to measure absolute conductivity.

All the above measurements were repeated three times, and the relative conductivity was the ratio of the conductivity of the leached solution before boiling to that after boiling.

\section{$\sim$ Determination of reactive oxygen content}

The determination of $\mathrm{H}_{2} \mathrm{O}_{2}$ content refers to the method of Xia Fangshan, [13].

$\mathrm{O}^{2-}$ produce speed measurement using the method of Gila Idelman,et al. [14], modified as follows: according to samples from $2 \mathrm{~g}$ hyphae after deionized water flushing in the mortar of the precooling, add $1.6 \mathrm{~mL} 0.05 \mathrm{~mol} \cdot \mathrm{mL}^{-1}$ phosphate buffer $(\mathrm{pH} 7.8)$ on an ice bath to homogenate, into the centrifuge tube at $4^{\circ} \mathrm{C}$, under the condition of $12000 \mathrm{rpm}$ centrifugal supernatant on $20 \mathrm{~min}$ take is the thick enzyme fluid. Take $0.5 \mathrm{~mL}$ thick enzyme fluid to add $0.5 \mathrm{~mL}$ phosphate buffer and $1 \mathrm{~mL}$ hydroxylamine chloride $25^{\circ} \mathrm{C}$ for $1 \mathrm{~h}$ reaction, add $1 \mathrm{~mL} \quad 0.017 \mathrm{~mol} \cdot \mathrm{L}^{-1}$ in aminobenzene sulfonic acid and $1 \mathrm{~mL}$ of $0.007 \mathrm{~mol} \cdot \mathrm{L}^{-1}$ alpha naphthylamine, under the condition of $25^{\circ} \mathrm{C}$ reaction 20min with phosphoric acid buffer instead of blank sample, the $530 \mathrm{~nm}$ wavelength photometric value, the use of sodium nitrite in the concentration 
of standard curve is obtained after conversion to speed again.

\section{(4) Data analysis}

GraphPad Prism 8.0 software was used for data sorting and plotting, and statistical software SPSS 25.0 was used for data sorting and analysis of the ages of three kinds of fungus and various physiological indexes of Auricularia auricula.

\section{RESULTS}

\subsection{Determination of the aging time of mycelium}

The growth rate of the three liquid spawn of Auricularia auricula was faster, with the increase of cultivation age, the growth rate of the hyphae of Auricularia auricula showed a trend of first increasing and then decreasing. It was obvious that the growth rate of the three species of Auricularia auricula increased gradually from 8 to $12 \mathrm{~d}$ old, and began to decline rapidly after $12 \mathrm{~d}$ old, indicating that with the beginning of aging, the growth rate of mycelia began to decline.( Figure 1-A)

Also as shown in Figure 1-B that with the increase of the cultivation age after inoculating of the mycelium the germination time was longer.

The average germination time of the three species of Auricularia auricula was $1.36 \mathrm{~d}$ on the $8^{\text {th }}$ day and $4.2 \mathrm{~d}$ on the $16^{\text {th }} \mathrm{d}$, which was $2.84 \mathrm{~d}$ different from the minimum germination time, indicating that the length of cultivation age had a great impact on the vigor of the strains. With the aging of the mycelia, the vigor of the strains decreased rapidly. Also as shown in Figure 1-C, with the increase of cultivation age, the growth weight of the three species showed a general trend of first increase and then decline. The growth weight of Hei29 and Heiweidanpian both reached their maximum in $14 \mathrm{~d}$. Heiweibanjin reached its maximum value on the $12^{\text {th }} \mathrm{d}$, and the growth was always the lowest, indicating that Heiweibanjin had the lowest growth and metabolism rate and the smallest activity.
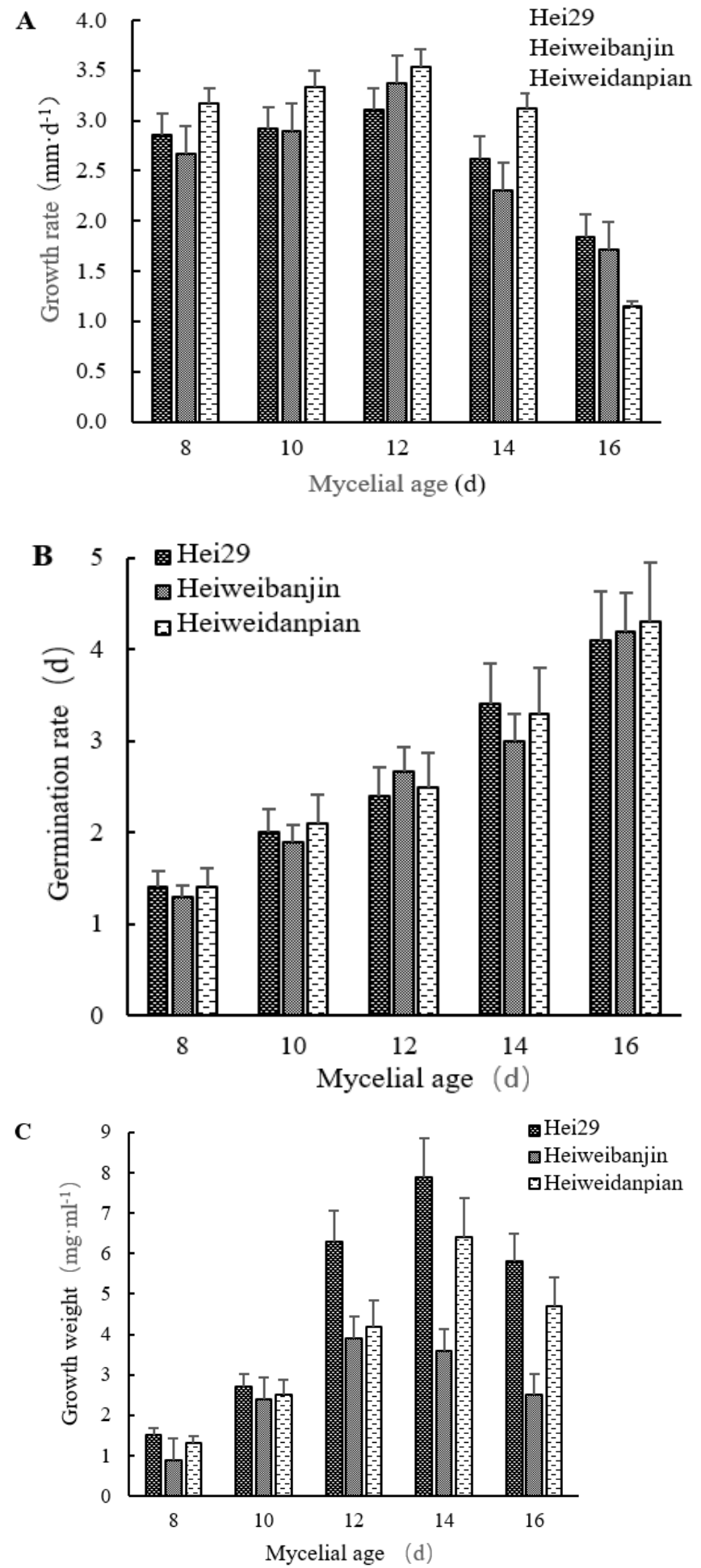

Figure 1 . The change of growth rate, germination time and growth weight in different mycelia age

\subsection{Changes in physiological indexes during aging 3.2.1 Antioxidant enzyme determination}

SOD has special physiological activity and is the primary material for scavenging free radicals in the organism. As shown in Figure 2-A, with the increase 
of cultivation age, SOD activity of the three species of Auricularia auricular showed an overall downward trend with obvious regularity. From 8 to $16 \mathrm{~d}$, the SOD activity of Hei29, Heiweibanjin and Heiweidanpian was decreased by $58 \%, 40 \%$ and $72 \%$ respectively. The decrease of SOD activity may be the main reason for the aging of Auricularia auricula.

The changes in POD activity are shown in Figure 2-B. With the increase of mycelia age, the changes in POD activity of the three kinds of Auricularia auricula are not the same. Hei29, Heiweibanjin both reached their maximum values on the $14^{\text {th }} \mathrm{d}$, and Heiweidanpian reached their maximum values on the $10^{\text {th }} d$, indicating that there was no regularity between POD and aging of Auricularia auricula, indicating that POD enzyme did not play a major role in the antiaging process of mycelium cells. As shown in Figure 2-C, the CAT activities of the three species of Auricularia auricula increased continuously with the increase of mycelia age, and the CAT activities of the three species of Auricularia auricula alternately took the lead. From 8 to 16d, the CAT activity of Hei29, Heiweibanjin and Heiweidanpian increased to 8.66, 5.48 and 3.28 times respectively. It can be seen that Auricularia auricula can resist aging by enhancing CAT enzyme activity.

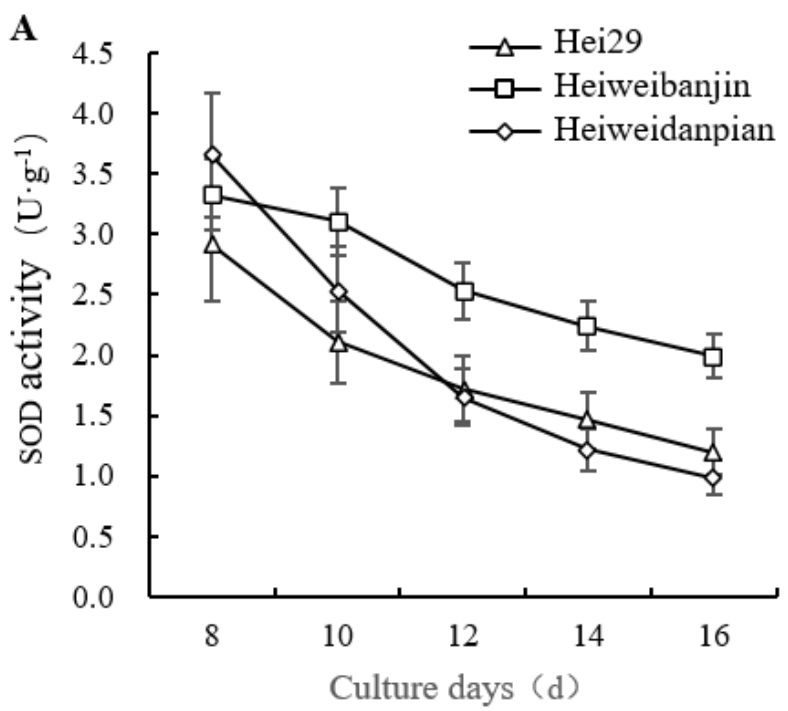

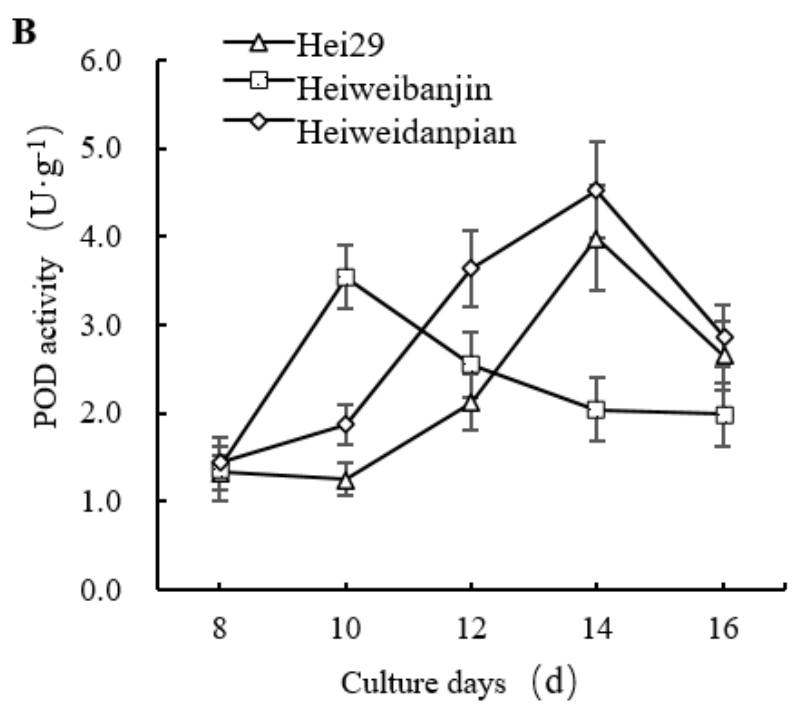

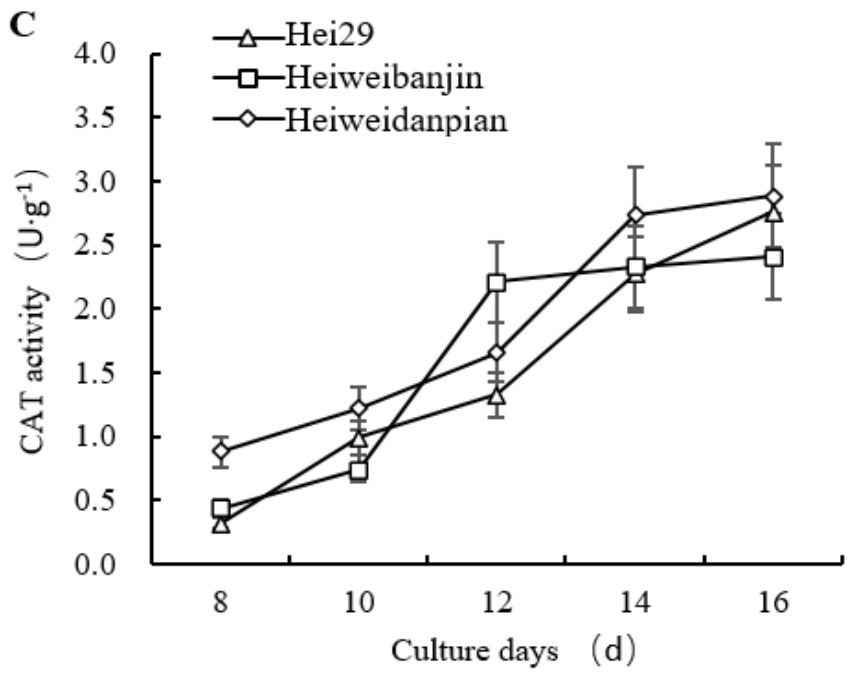

Figure 2. Changes of SOD, POD and CAT activities in different culture days

\subsubsection{Determination of non-enzymatic antioxidant substances}

As shown in Figure 3-A, the ASA content of Hei29, Heiweibanjin and Heiweidanpian increased slowly after the beginning of aging on the $12^{\text {th }} \mathrm{d}$, and reached the maximum value on the $16^{\text {th }} \mathrm{d}$, which was 226,204 and $237 \mathrm{mg} \cdot 100 \mathrm{~g}^{-1}$, respectively. Compared with the $8^{\text {th }}$ day, the ASA secretion was significantly increased, indicating that the increase and decrease of mycelium activity did not affect the secretion of ASA. Proline content changes as shown in Figure $3-\mathrm{B}$, the content of proline in the hyphae of three species of Auricularia auricula showed a decreasing trend with 
the increase of mycelia age, and in $8 \sim 16 \mathrm{~d}$ change is not obvious little ups and downs, the maximum time is different also, proline content of Hei29, Heiweibanjin and Heiweidanpian in 10d respectively, reach maximum 8 and $14 \mathrm{~d}$, no regularity.

This change indicated that the agaric fungus may begin to use its nutrition to consume proline to resist aging.
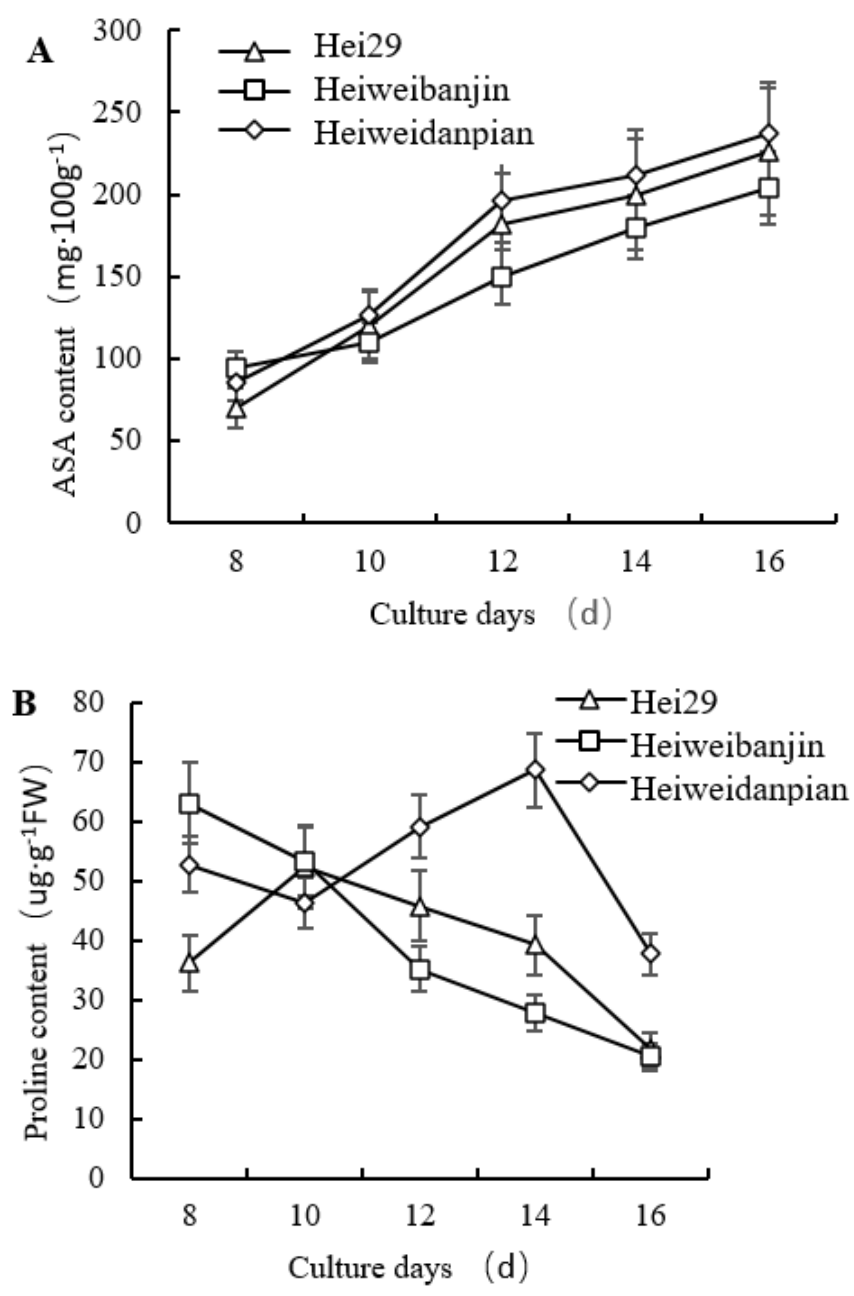

Figure 3. Changes of ASA and Proline content in different culture days.

\subsubsection{Determination of membrane lipid peroxidation} degree

The change of MDA content of the three species of Auricularia auricula is shown in Figure 4-A, with the same overall change pattern and an upward trend. It can be seen that with the aging process, active oxygen free radicals continue to accumulate and the degree of membrane lipid peroxidation continues to deepen. However, the growth rate of the three kinds of Auricularia auricula was similar in different culture time.

The relative electrical conductivity of the three species of Auricularia auricula is shown in Figure 4-B. Generally, the relative electrical conductivity of the three species of Auricularia auricula is not the same, and the variation range is also different between different mycelia ages. In particular, the relative conductivity of Hei29 was almost unchanged during the incubation period of $8 \sim 16 \mathrm{~d}$. Although the changes of Heiweibanjin and Heiweidanpian were obvious at different times, they were high and low at different times, and the maximum value was not at the same culture time, which showed no regularity, indicating that although the degree of membrane lipid peroxidation was continuously deepening, the permeability of the membrane was not significantly damaged.

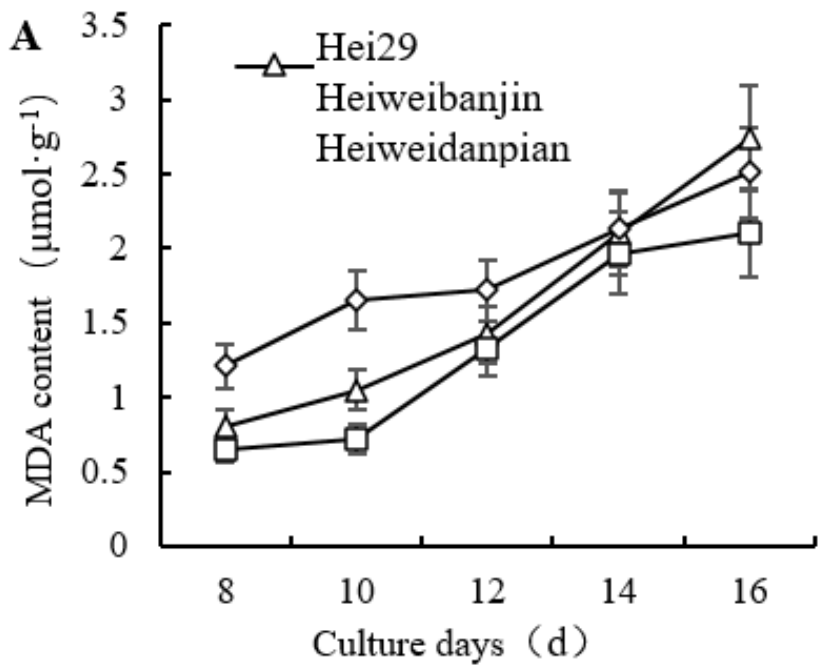




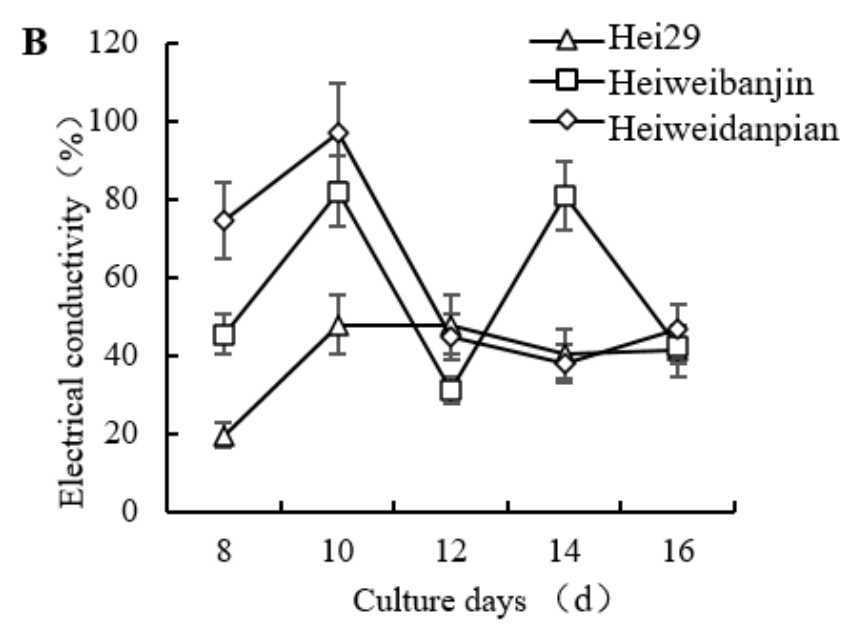

Figure 4. Changes of MDA content and electrical conductivity in different culture days.

\subsubsection{Determination of reactive oxygen species}

As shown in Figure 5-A, the three species of Auricularia auricula $\mathrm{H}_{2} \mathrm{O}_{2}$ content as a whole are increased with the increase of fungus age showed a trend of decline after rising first, and achieve the lowest in $12 \mathrm{~d}$, only the Heiweidanpian in $8 \sim 12 \mathrm{~d}$ fluctuated, the three species of Auricularia auricula rapidly rising after $12 \mathrm{~d}$, shows that antioxidant enzymes and the enzyme before aging antioxidants can keep clear of $\mathrm{H}_{2} \mathrm{O}_{2}$, but after aging for $\mathrm{H}_{2} \mathrm{O}_{2}$ removal ability drops rapidly. The production rates of superoxide anion free radicals of three species of Auricularia auricula of different mycelia ages are shown in Figure 5-B. With aging, the production rates of superoxide anion free radicals are increasing and the rate of increase is gradually increasing. It indicated that the ability of the fungus hyphae to scavenging superoxide anion free radicals was gradually weakened, and the superoxide anion free radicals were accumulating continuously.
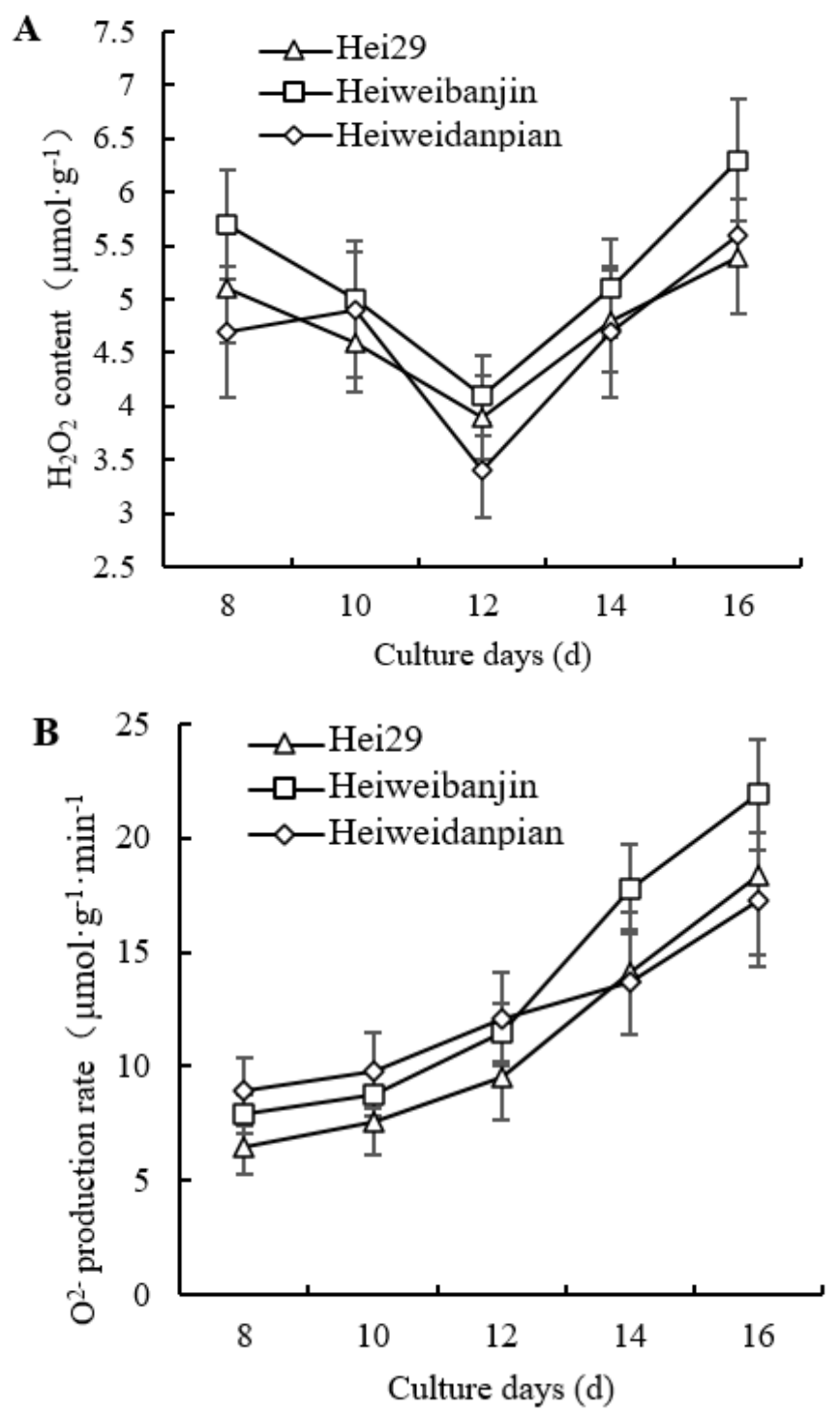

Figure 5. Changes of $\mathrm{H}_{2} \mathrm{O}_{2}$ content and $\mathrm{O}^{2-}$ Production rate in different culture days.

\subsubsection{The Quantitative analysis of physiological indexes in different mycelia age}

Table1 and Table2 is showed the CAT activity, ASA content, MDA content and $\mathrm{O}^{2-}$ production rate of the three kinds of Auricularia auricula all gradually increase with the increase of mycelia age.

Table 1. Changes of antioxidant enzymes and antioxidant substances in the process of $A$. auricula aging

\begin{tabular}{ccccccc}
\hline Species & Age & SOD & POD & CAT & ASA content & Pro content \\
\hline 8 & $2.91 \pm 0.11$ & $1.33 \pm 0.06$ & $0.32 \pm 0.15 \mathrm{eE}$ & $70 \pm 4.58 \mathrm{eE}$ & $36.2 \pm 1.28$ \\
& $\mathrm{aA}$ & $\mathrm{dD}$ & & & $\mathrm{dD}$ \\
& 10 & $2.11 \pm 0.11$ & $1.25 \pm 0.05$ & $0.99 \pm 0.11$ & $120 \pm 2.65 \mathrm{dD}$ & $52.3 \pm 0.20$ \\
& $\mathrm{bB}$ & $\mathrm{dD}$ & $\mathrm{dD}$ & & $\mathrm{aA}$
\end{tabular}




\begin{tabular}{|c|c|c|c|c|c|c|}
\hline Hei29 & 12 & $1.72 \pm 0.02$ & $2.12 \pm 0.11$ & $1.33 \pm 0.06 \mathrm{eE}$ & $182 \pm 4.00 \mathrm{cC}$ & $45.8 \pm 0.89$ \\
\hline & & $\mathrm{cC}$ & $\mathrm{cC}$ & & & $\mathrm{bB}$ \\
\hline & 14 & $1.46 \pm 0.14 \mathrm{dD}$ & $3.99 \pm 0.15$ & $2.27 \pm 0.09$ & $200 \pm 7.81 \mathrm{bB}$ & $39.2 \pm 0.66$ \\
\hline & & & $\mathrm{aA}$ & $\mathrm{bB}$ & & $\mathrm{cC}$ \\
\hline & 16 & $1.20 \pm 0.07 \mathrm{eE}$ & $2.65 \pm 0.04$ & $2.77 \pm 0.13$ & $226 \pm 3.46 \mathrm{aA}$ & $21.6 \pm 0.56$ \\
\hline & & & bB & $\mathrm{aA}$ & & $\mathrm{eE}$ \\
\hline & 8 & $3.33 \pm 0.11 \mathrm{aA}$ & $1.37 \pm 0.11$ & $0.44 \pm 0.07$ & $94 \pm 5.57 \mathrm{eE}$ & $63.1 \pm 0.72$ \\
\hline & & & $\mathrm{dD}$ & $\mathrm{dD}$ & & $\mathrm{aA}$ \\
\hline & 10 & $3.11 \pm 0.11$ & $3.54 \pm 0.07$ & $0.75 \pm 0.04$ & $110 \pm 7.00 \mathrm{dD}$ & $53.3 \pm 0.74$ \\
\hline & & bB & $\mathrm{aA}$ & $\mathrm{cC}$ & & bB \\
\hline Heiweibanjian & 12 & $2.53 \pm 0.09$ & $2.55 \pm 0.09$ & $2.21 \pm 0.07$ & $150 \pm 10.15 c C$ & $35.2 \pm 0.66$ \\
\hline & & $\mathrm{cC}$ & bB & $\mathrm{bB}$ & & $\mathrm{cC}$ \\
\hline & 14 & $2.24 \pm 0.05$ & $2.04 \pm 0.13$ & $2.32 \pm 0.05 \mathrm{aB}$ & $180 \pm 6.00 \mathrm{bB}$ & $27.8 \pm 0.36$ \\
\hline & & $\mathrm{dD}$ & $\mathrm{cC}$ & & & $\mathrm{dD}$ \\
\hline & 16 & $1.99 \pm 0.11 \mathrm{eE}$ & $1.99 \pm 0.09$ & $2.41 \pm 0.05$ & $204 \pm 7.55 \mathrm{aA}$ & $20.3 \pm 0.64$ \\
\hline & & & $\mathrm{cC}$ & $\mathrm{aA}$ & & $\mathrm{eE}$ \\
\hline & 8 & $3.69 \pm 0.07$ & $1.45 \pm 0.07 \mathrm{eE}$ & $0.93 \pm 0.09$ & $85 \pm 8.54 \mathrm{dD}$ & $52.70 \pm 0.66$ \\
\hline & & $\mathrm{aA}$ & & $\mathrm{dD}$ & & $\mathrm{cC}$ \\
\hline & 10 & $2.54 \pm 0.05$ & $1.84 \pm 0.10 \mathrm{dD}$ & $1.22 \pm 0.09$ & $126 \pm 7.00 \mathrm{cC}$ & $46.17 \pm 0.21$ \\
\hline & & $\mathrm{bB}$ & & $\mathrm{cC}$ & & $\mathrm{dD}$ \\
\hline Heiweidanpian & 12 & $1.65 \pm 0.11$ & $3.64 \pm 0.10$ & $1.66 \pm 0.06$ & $196 \pm 13.12$ & $59.10 \pm 0.87$ \\
\hline & & $\mathrm{cC}$ & bB & bB & $\mathrm{bB}$ & bB \\
\hline & 14 & $1.22 \pm 0.06 \mathrm{dD}$ & $4.53 \pm 0.07$ & $2.73 \pm 0.09$ & $212 \pm 5.57 \mathrm{bB}$ & $68.53 \pm 0.49$ \\
\hline & & & $\mathrm{aA}$ & $\mathrm{aA}$ & & $\mathrm{aA}$ \\
\hline & 16 & $0.99 \pm 0.05 \mathrm{eE}$ & $2.88 \pm 0.09$ & $2.89 \pm 0.07 \mathrm{aA}$ & $237 \pm 10.44$ & $37.70 \pm 0.26$ \\
\hline & & & $\mathrm{cC}$ & & $\mathrm{aA}$ & $\mathrm{eE}$ \\
\hline
\end{tabular}

Note: Capital and lowercase letters indicate significant differences at the level of 0.01 and 0.05 in the table, respectively.

Also, CAT activity, ASA content and $\mathrm{O}^{2-}$ production rate of the three species of Auricularia auricula all increased significantly from 8 to 12d, and these three indexes of Hei29 all increased significantly from 8 to $16 \mathrm{~d}$.

Table 2. Changes of membrane peroxidation degree and active oxygen in the process of $A$. auricula aging

\begin{tabular}{cccccc}
\hline Species & Age & MDA content & $\begin{array}{c}\text { Electrical } \\
\text { conductivity }\end{array}$ & $\begin{array}{c}\mathrm{O}^{2-} \text { production } \\
\text { rate }\end{array}$ & $\mathrm{H}_{2} \mathrm{O}_{2}$ content \\
\hline & 8 & $0.81 \pm 0.07 \mathrm{eD}$ & $19.47 \pm 0.06 \mathrm{dD}$ & $6.5 \pm 0.11 \mathrm{aB}$ & $5.1 \pm 0.36 \mathrm{eE}$ \\
& 10 & $1.05 \pm 0.19 \mathrm{dA}$ & $47.87 \pm 0.03 \mathrm{aA}$ & $7.6 \pm 0.10 \mathrm{cC}$ & $4.6 \pm 0.26 \mathrm{dD}$ \\
$\mathrm{Hei} 29$ & 12 & $1.42 \pm 0.06 \mathrm{cA}$ & $47.83 \pm 0.04 \mathrm{aA}$ & $9.5 \pm 0.08 \mathrm{dD}$ & $3.9 \pm 0.10 \mathrm{cC}$ \\
& 14 & $2.10 \pm 0.07 \mathrm{bC}$ & $40.42 \pm 0.06 \mathrm{cC}$ & $14.1 \pm 0.08 \mathrm{bC}$ & $4.8 \pm 0.10 \mathrm{bB}$ \\
& 16 & $2.74 \pm 0.05 \mathrm{aB}$ & $41.11 \pm 0.07 \mathrm{bB}$ & $18.4 \pm 0.06 \mathrm{aA}$ & $5.4 \pm 0.17 \mathrm{aA}$ \\
\hline
\end{tabular}




\begin{tabular}{lccccc}
\hline & 8 & $0.65 \pm 0.11 \mathrm{cC}$ & $45.45 \pm 0.10 \mathrm{cC}$ & $7.9 \pm 0.11 \mathrm{eE}$ & $5.7 \pm 0.20 \mathrm{bB}$ \\
Heiweibanjian & 10 & $0.72 \pm 0.15 \mathrm{cC}$ & $81.97 \pm 0.06 \mathrm{aA}$ & $8.8 \pm 0.12 \mathrm{dD}$ & $5.0 \pm 0.26 \mathrm{cC}$ \\
& 12 & $1.33 \pm 0.33 \mathrm{bB}$ & $31.09 \pm 0.07 \mathrm{eE}$ & $11.5 \pm 0.10 \mathrm{cC}$ & $4.1 \pm 0.10 \mathrm{dD}$ \\
& 14 & $1.97 \pm 1.97 \mathrm{aA}$ & $80.83 \pm 0.06 \mathrm{bB}$ & $17.8 \pm 0.13 \mathrm{bB}$ & $5.1 \pm 0.23 \mathrm{cC}$ \\
& 16 & $2.11 \pm 2.11 \mathrm{aA}$ & $42.50 \pm 0.08 \mathrm{dD}$ & $21.9 \pm 0.08 \mathrm{aA}$ & $6.3 \pm 0.20 \mathrm{aA}$ \\
\hline \multirow{6}{*}{ Heiweidanpian } & 8 & $1.21 \pm 0.05 \mathrm{dD}$ & $74.53 \pm 0.02 \mathrm{bB}$ & $8.9 \pm 0.09 \mathrm{eE}$ & $4.7 \pm 0.20 \mathrm{bB}$ \\
& 10 & $1.65 \pm 0.05 \mathrm{cC}$ & $97.01 \pm 0.09 \mathrm{aA}$ & $9.8 \pm 0.06 \mathrm{dD}$ & $4.9 \pm 0.44 \mathrm{bB}$ \\
& 12 & $1.72 \pm 0.05 \mathrm{cC}$ & $44.55 \pm 0.11 \mathrm{dD}$ & $12.1 \pm 0.10 \mathrm{cC}$ & $3.4 \pm 0.17 \mathrm{cC}$ \\
& 14 & $2.13 \pm 0.09 \mathrm{bB}$ & $38.12 \pm 0.10 \mathrm{eE}$ & $13.7 \pm 0.08 \mathrm{bB}$ & $4.7 \pm 0.10 \mathrm{bB}$ \\
& 16 & $2.51 \pm 0.13 \mathrm{aA}$ & $46.88 \pm 0.08 \mathrm{cC}$ & $17.3 \pm 0.13 \mathrm{aA}$ & $5.6 \pm 0.26 \mathrm{aA}$ \\
\hline
\end{tabular}

Note: Capital and lowercase letters indicate significant differences at the level of 0.01 and 0.05 in the table, respectively.

The SOD activity of the three species decreased gradually with the increase of mycelia age, and the SOD activity of all species decreased significantly from 8 to $16 \mathrm{~d}$. Although the Pro content and electrical conductivity of the three kinds of Auricularia auricula had different trends, they were significantly decreased from 14 to $16 \mathrm{~d}$ and significantly increased from 8 to $10 \mathrm{~d}$, respectively, and $\mathrm{H}_{2} \mathrm{O}_{2}$ content was significantly increased from 12 to $16 \mathrm{~d}$.

According to the data in the table, when the content of MDA is $1.42^{\sim} 1.72 \mu \mathrm{mol} \cdot \mathrm{g}^{-1}$, the content of $\mathrm{H}_{2} \mathrm{O}_{2}$ is $3.4^{\sim} 4.3 \mu \mathrm{mol} \cdot \mathrm{g}^{-1}$, the production rate of $\mathrm{O}^{2-}$ is 9.5 $12.1 \mu \mathrm{mol} \cdot \mathrm{g}^{-1} \cdot \mathrm{min}^{-1}$, it can be considered that the Auricularia auricula is just about to enter the aging stage or the aging degree is low.

\section{DISCUSSION}

In this study, we investigated the aging age of liquid spawn of the three species Auricularia auricula (Hei29, Heiweibanjin, and Heiweidanpian) and the changes of antioxidant enzymes, antioxidant substances, membrane peroxidation degree and reactive oxygen concentration with different cultivate age. Figure 1A, B, C showed that with the increase of the culture time, the germination rate of the same Auricularia auricula gradually increased after being transferred to a new plate medium, and the growth rate and growth rate increased first and then decreased, and the three indicators began to decline on average at $12 \mathrm{~d}$, and it can be determined that the mycelial viability began to decline at $12 \mathrm{~d}$, and the aging phenomenon began to appear.

The germination rate of the three kinds of Auricularia auricula is similar to that of the same mycelia age, and the germination time and growth rate of the three kinds of Auricularia auricula are relatively low when the mycelia age starts at $8 \mathrm{~d}$. Among them, the average germination rate was $1.4 \mathrm{~d}$, and the average germination rate was $4.2 \mathrm{~d}$ when transferred on the $16^{\text {th }} \mathrm{d}$. It may be because the hyphae gradually decrease in vigor and the germination speed gradually increases with the increase of the mycelia age. The slower increase speed may be due to the poor adaptability of the hypha to the new plate medium. The growth rate rises slowly in 8 to $12 \mathrm{~d}$ and then decreases rapidly. It may be that the antioxidant system gradually collapses after aging, and the aging rate is getting faster and faster. The growth of the three types of Auricularia auricula increased first and then increased, indicating that the hyphae were not aging in the early stage, with sufficient nutrients, strong vitality, strong metabolism, and high 
utilization of nutrients. However, with the onset of aging, growth begins to decline, which may be due to the lack of nutrients in the later stage, the mycelium resists aging by decomposing its own nutrients, or the degree of oxidation of the cell membrane is higher, the permeability increases, and the content of small molecules flows out.

The removal of reactive oxygen species by aerobic organisms is mainly accomplished by enzymatic scavengers-superoxide dismutase (SOD), catalase (Catalase, CAT), and peroxidase (POD) [15].

Figure 2-A showed that with the increase of mycelia age, the changing trend of SOD enzymes of the three Auricularia auricula gradually decreases, and it can be seen that SOD activity has a certain regularity with the aging of the three Auricularia auricula. Also, Figure 2-B, C have shown that during the aging process of Auricularia auricula, mycelium can resist the damage caused by aging by enhancing the activity of CAT, POD has the dual effect of eliminating the toxicity of hydrogen peroxide and phenols, amines, aldehydes, and benzene. However, the POD enzyme activity does not have certain regularity in the different periods of the three Auricularia auricula. It can be seen that the POD enzyme in the Auricularia auricula does not play a key role in the anti-aging process.

Previous studies have shown that ascorbic acid is an important antioxidant, and ascorbic acid can scavenge O2-, OH-, and ROO- free radicals [16].

Figure 3-A have shown the ASA content increased with the increase of cultivating age, and the three Auricularia auricula showed an overall upward trend, which may be due to the enhancement of respiration or the decrease of decomposing enzyme activity, but the trend of change was different at different times, indicating that ascorbic acid is in the anti-aging process plays a key role [13].
Figure 3-B has shown the proline content of the three kinds of Auricularia auricula hyphae showed a downward trend with the aging time of Auricularia auricula, but the proline content of the Heiweibanjin strain fluctuated slightly, and there was no obvious change rule.

MDA is one of the products of membrane lipid peroxidation. The increase of MDA will aggravate the degree of membrane lipid peroxidation, damage the structure of biomembrane, and increase the permeability of the cell membrane. Figure 4-A showed that with the increase of the mycelia age, the MDA content of the three Auricularia auricula continued to increase, showing a certain regularity with the mycelia age. It shows that the continuous increase of MDA content accelerates the accumulation of toxic substances, thereby intensifying the degree of lipid peroxidation of cell membranes.

Figure 4-B showed the electrical conductivity of the three kinds of Auricularia auricula with the increase of mycelia age, with high and sometimes low, with no obvious regularity. Theoretically, as the aging progresses, the degree of membrane lipid peroxidation will deepen, the cell membrane will be destroyed, and the permeability will increase. The soluble small molecules such as minerals and inorganic salts in the mycelial cells will leak out. The electrical conductivity will increase [17], but the results of this experiment are not regular. The possible reason is that although the cell membrane permeability of the Auricularia auricula hyphae increases during the aging process, the cell membrane has adapted to this growth state due to the long-term liquid environment. The impact on the cell membrane becomes smaller, so the relative conductivity cannot be used to reflect the aging of the liquid spawn of Auricularia auricula.

The lipid peroxidation reaction between ROS and biological membranes to form lipid peroxidation products changes the fluidity and permeability of cell 
membranes, which in turn leads to changes in cell structure and function [18]. ROS mainly includes superoxide radical $\left(\mathrm{O}^{2-}\right)$, hydroxyl radical $(-\mathrm{OH})$ and hydrogen peroxide $\left(\mathrm{H}_{2} \mathrm{O}_{2}\right)$, etc. [19]. Figure 5-A showed that with the progress of aging, the hydrogen peroxide content of the three Auricularia auricula first decreased slowly, and then increased rapidly, which was irregular with the mycelia age, indicating that the continuous increase of catalase did not accelerate the $\mathrm{H}_{2} \mathrm{O}_{2}$ effect of Auricularia auricula hyphae. Figure 5-B showed the scavenging ability of superoxide anion free radicals continues to increase, which has a significant regularity with aging. It can be seen that the ability of three Auricularia auricula to scavenging $\mathrm{O}^{2-}$ declines rapidly after aging, which may be due to the continuous decline of SOD activity and the inability to clear $\mathrm{O}^{2-}$ in time, which will further deepen the degree of membrane lipid peroxidation, leading to accelerated aging. Table1 and Table2 are showed the quantitative analysis of physiological indexes in different mycelia age, it can be seen that the Auricularia auricula is just about to enter the aging stage or the aging degree is low.

\section{CONCLUSION}

We have studies changes of physiological characteristic indexes in the aging process of the liquid spawn of Auricularia auricula. In this paper, were analyzed the changes of antioxidant enzymes, antioxidant substances, membrane peroxidation degree, and active oxygen concentration of the three species Auricularia auricula during different mycelia age. The results showed that, at the same mycelia age, the activity of the single tablet was the strongest, followed by the single-tablet, followed by the single tablet, and the single tablet was the weakest. ASA content, $\mathrm{MDA}$ content and $\mathrm{O}^{2-}$ production rate increased with the increase of mycelia age, while SOD activity decreased with the increase of mycelia age. When the content of MDA was $1.42^{\sim} 1.72 \mu \mathrm{mol} \cdot \mathrm{g}$ 1, the content of $\mathrm{H}_{2} \mathrm{O}_{2}$ was $3.4^{\sim} 4.3 \mu \mathrm{mol} \cdot \mathrm{g}^{-1}$, or the production rate of $\mathrm{O}^{2-}$ was $9.5^{\sim} 12.1 \mu \mathrm{mol} \cdot \mathrm{g}^{-1} \mathrm{~min}^{-1}$, it was considered that Auricularia auricula was just about to enter the aging stage or the aging degree was low.

\section{REFERENCES}

[1]. Fang Jie Yao, Li-Xin Lu, et al. Development of a Molecular Marker for Fruiting Body Pattern in Auricularia auricula-judae, Mycobiology. 2018, 46(1): 72-78.

[2]. Andrea Hamann, et al. Apoptosis pathways in fungal growth, development and ageing. Trends in Microbiology, 2008, 16(6):276-283.

[3]. Heinz D Osiewacz. Aging in fungi: role of mitochondria in Podospora anserine. Mechanisms of Ageing and Development, 2012, 123(7):755-764

[4]. Ahmad P, Jaleel C A, Salem M A, et al. Roles of enzymatic and nonenzymatic antioxidants in plants during abiotic stress. Critical Reviews in Biotechnology, 2010, 30(3): 161-175.

[5]. Zhang Y. The Research of Reactive Oxygen Species (ROS) in plants. Current Biotechnology, 2011, 1(4): 242-248.

[6]. Namal P, et al. Phagocytosis enhancement, endotoxin tolerance, and signal mechanisms of immunologically active glucuronoxylomannan from Auricularia auricula-judae, International Journal of Biological Macromolecules, 2020, 165:495-505

[7]. Liu Zhanli, et al. Changes in color, antioxidant, and free radical scavenging enzyme activity of mushrooms under high oxygen modified atmospheres, Postharvest Biology and Technology. 2012, 69:1-6.

[8]. Xu Jie, et al. Salinity relief aniline induced oxidative stress in Suaeda salsa: Activities of antioxidative enzyme and EPR measurements. Ecotoxicology and Environmental Safety, 2020, 205:35-45

[9]. Hameed A, Iqbal N, Malik S A. Mannoseinduced modulations in antioxidants, protease activity, lipid peroxidation, and total 
phenolics in etiolated wheat leaves. Journal of plant growth regulation, 2009, 28(1): 58-65.

[10]. Tai T H. Evaluation of seedling cold tolerance in rice cultivars: a comparison of visual ratings and quantitative indicators of physiological changes. Euphytica, 2011, 178(3): 437-447.

[11]. Madosa Emilian, et al. Studies on drought tolerance assessed by testing proline content in pepper (Capsicum annuum L.). Current Opinion in Biotechnology, 2013, 24:56-63

[12]. Mohammad Rezaee,et al. Development of an electrical conductivity screening test for mine waste assessments. Chemosphere, 2016, 160:1321.

[13]. Xia Fangshan, et al. Effects of non-enzymatic scavengers of reactive oxygen species on aging seeds, Pratacultural Science 2016, 33 (6), 11261135.

[14]. Gila Idelman,et al. Bilirubin inhibits the upregulation of inducible nitric oxide synthase by scavenging reactive oxygen species generated by the toll-like receptor 4-dependent activation of NADPH oxidase. Redox Biology, 2015, 5:398-408

[15]. Yin Yahui, An Wentao, et al. Changes of antioxidant enzyme activities in different algebraic of Saccharomyces cerevisiae, Food Science and Technology, 2013, 38(8):38-47.

[16]. Jiang $M$, et al. Antioxidant effects of proline accumulation in rice seedlings under oxidative stress, Journal of Plant Physiology, 1997, (4):347-352.

[17]. Preeya Kaewnaree, et al. Electrolyte leakage and fatty acid changing associated with seed germination in accelerated aging sweet pepper seeds. Journal of Biotechnology, 2008, 136:108121.

[18]. Pasquini S, Mizzou M, et al. Seed storage in polyethylene bags of a recalcitrant species (Quercus ilex): analysis of some bio-energetic and oxidative parameters. Acta physiological Plantarum. 2012， 34(5):1963-1974.
[19]. Botella, M. A, Rosado. A, et al. Plant adaptive responses to salinity stress. Plant abiotic stress. 2005(1):37-70.

\section{Cite this article as :}

Jong Chol, Jin MyongIl, Choe SunIl, Zhu HaiFeng, Li DeTian, Jo TaeYun, Kim GyongChol, "Changes of Physiological Characteristic Indexes in the Aging Process of the Liquid Spawn of Auricularia auricula ", International Journal of Scientific Research in Science, Engineering and Technology (IJSRSET), Online ISSN : 2394-4099, Print ISSN : 2395-1990, Volume 8 Issue 1, pp. 204-215, January-February 2021. Available at doi $\quad$ : https://doi.org/10.32628/IJSRSET218141 Journal URL : https://ijsrset.com/IJSRSET218141 